\title{
Power Supply Reliability Indexes
}

\author{
Felix Byk, Lyudmila Myshkina \\ Automated Electrical Power Systems department \\ Novosibirsk State Technical University, NSTU \\ Novosibirsk, Russia \\ 1-zakirova@yandex.ru
}

\author{
Ksenia Khokhlova \\ Power Stations department \\ Novosibirsk State Technical University, NSTU \\ Novosibirsk, Russia
}

\begin{abstract}
Reliability of the power system depends on coordination and coherence of continuous processes of production, transmission, distribution and consumption of electric energy. It is offered to consider a power supply system of Russia as a four-level hierarchical system due to the terms of uninterrupted operation of power supplies. For each hierarchical level, there is a system of indexes, reflecting the role of the backbone, transmission and distribution networks. The authors offer to calculate reliability indexes of power supply - regional's group supply points, district centers of supply, local supply points and end-consumers. Indexes cover structural, object and regime parameters of an electrical network. This approach makes it possible to determine bottlenecks, to select and to justify the ways and means of improving the power system reliability without reducing their efficiency.
\end{abstract}

Keywords-reliability; system; index; indicator; power supply

\section{SITUATION ANALYSIS AND PROBLEM DEFINITION}

It is known that a combination of reliability and profitability forms efficiency of a power supply system. Therefore, the efficiency index, reflecting usefulness of a power system, can be determined by the known function of Cobb - Douglas:

$$
\mathrm{I}_{\mathrm{c}}=\mathrm{I}_{\mathrm{e}}{ }^{\mathrm{n}} \cdot \mathrm{I}_{\mathrm{r}}^{\mathrm{m}} \text {, }
$$

where $I_{c}$ - efficiency index,

$\mathrm{I}_{\mathrm{e}}$ - profitability index,

$\mathrm{I}_{\mathrm{r}}$ - reliability index,

$\mathrm{n}+\mathrm{m}=1$.

The index of profitability $I_{e}$ raises in case of the reduction of costs of production, transmission and distribution of electricity, and the index of reliability $I_{r}$ increases with the reduction of depth, frequency and duration of switch-offs and the imposed restrictions for a power consumption. The ratio of $\mathrm{n}$ and $\mathrm{m}$ reflects the value of each of two properties. Their choice defines priorities of development of power supply systems. For example, for Soviet period, $m \gg n$ ratio was characteristic, and the searching of the way to change the situation was the purpose of the market reform, undertaken in power industry.

Obviously, increasing $I_{r}$, which demands certain expenses, leads at the same time to reducing $\mathrm{I}_{\mathrm{e}}$. However, in Russia a decrease of both profitability and reliability of power supply is observed. Currently, a constant growth of electricity costs takes place and, regarding the reliability; annually over 24 thousand failures occur on power generation facilities, 700 of them are considered as serious, and more than 50 - have severe consequences [1].

In market relations, in countries with economic competition of power industry subjects, the level of power supply reliability is strictly watched. It allows deriving system effect, which means a profitability increase without a reliability decrease. Interconnection of separate regional power systems into the United Power System (UPS) is the most common way to gain the system effect. To provide system interconnection in Europe and the USA, trunk lines on a direct current are widely used, while in Russia it was carried out in extra high voltage AC lines.

The main subject of power industry, which implements the technical policy of interconnection in Russia, is PJSC "Federal Grid Company of United Power System" (FGC UPS). The state provides the development of a unified national power grid (UNPG). By strengthening the UNEG, the state not only increases the reliability of power system parallel operation of energy systems, but also allows starting the mechanism of the competition between the generation companies within the Russian wholesale market of the electric power.

As a result of strengthening of UNPG, it is possible to point out the reduction of number of "Zones of free flow of electricity" in Pooled Power Systems (PPS) and the significant power reserve growth. The total power reserve size in the UPS is currently over $30 \%$ [2], which allows having a high index of a balance reliability level, according to the annual reports of "System Operator of the United Power System". Besides, PJSC "FGC UPS" successfully solves the problem of improving the reliability of the UNPG. Constantly the number of technological violations in UNPG decreases, which makes it possible to provide parallel operation stability of power plants in the area of UPS.

Reliability problems of power supply are largely defined by the current state of regional power supply systems (RPSS). Nowadays RPSS represents a set of substations, called district centers of power supply (DC), and the uniting network of them, consisting generally of high voltage overhead transmission lines (OTL) of 110-220 kV. The combination of 
OTL forms a regional network with a meshed structure, which allows providing mutual back-up of them.

TABLE I. 100 KV OVERHEAD LINE FAILURE RATE PER SPAN IN 1984 AND 2015

\begin{tabular}{|c|c|c|c|}
\hline Company & 1984 & 2015 & $\begin{array}{c}\text { Change, } \\
\%\end{array}$ \\
\hline $\begin{array}{l}\text { "Buryatenergo", Branch of PJSC } \\
\text { "IDGC of Siberia" }\end{array}$ & \multirow{7}{*}{0.003705} & 0.010410 & 280 \\
\hline $\begin{array}{l}\text { "Omskenergo", Branch of } \\
\text { "IDGC of Siberia" }\end{array}$ & & 0.011830 & 320 \\
\hline $\begin{array}{l}\text { "Chechenenergo", Branch of PJSC } \\
\text { "IDGC of the North Caucasus" }\end{array}$ & & 0.026538 & 720 \\
\hline $\begin{array}{l}\text { Ingush branch of PJSC "IDGC of the } \\
\text { North Caucasus" }\end{array}$ & & 0.02480 & 670 \\
\hline $\begin{array}{l}\text { Karachay-Cherkessia branch of PJSC } \\
\text { "IDGC of the North Caucasus" }\end{array}$ & & 0.037579 & 1010 \\
\hline$\cdots$ & & $\ldots$ & ... \\
\hline $\begin{array}{l}\text { The average for the companies } \\
\text { analized }\end{array}$ & & 0.023288 & 630 \\
\hline
\end{tabular}

It is obvious that the reliability of power supply of DC is defined by conditions of a transmission line. According to statistics, the reliability of such network is reducing (Table 1) and can only be increased by improving of no-failure operation and recoverability of OTL [3]. There are relevant regional network organizations (RNO) in each region, which provide development and correct operation of the regional system. RNO are united in the multiregional network companies (MRNC) which are a part of PJSC "Rosseti" and belong to this subject of power industry. Therefore, the problem of ensuring the required reliability level of the areal point of power supply is assigned to regional branches of MRNC.

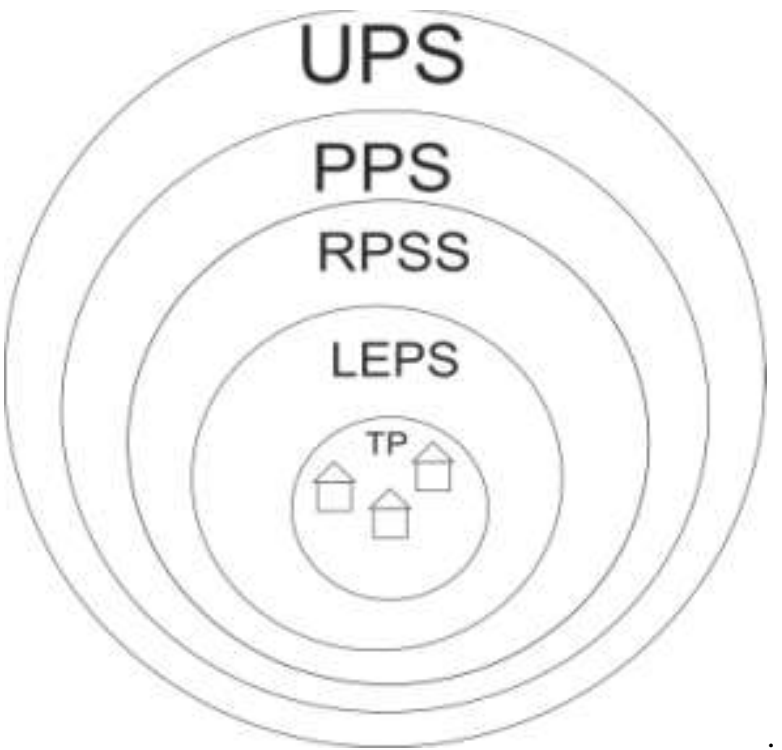

Fig. 1. The existing view of the power system.

Most of the reliability problems arise in location electric power systems (LEPS). They represent transformer points
(TP) connected by overhead and cable distribution lines of 6$35 \mathrm{kV}$ with regional DC. It is obvious that the number of LEPS in each region is equal to the number of DCs.

Reliability of power supply of consumers, located in the area of LEPS, depends on the reliability of power supply of TPs, as the bulk of consumers is connected by networks of 0.4 $\mathrm{kV}$ to TPs which are the nearest to them. LEPS is proposed to consider the lowest hierarchical level in the structure of the PPS and the primary element of the power supply system of consumers. The reliability of LEPS largely determines the degree of supply of uninterrupted supply to consumers.

It is obvious that control and regulation require development of the regulatory base for determination of profitability and reliability indexes of the power supply system. It is offered to consider UPS as a four-level hierarchical power supply system and to perform calculations of the relevant indexes and the analysis of reliability for each level. The article proposes a method for calculating a reliability index for a system consisting of a set of LEPS that are part of the regional RPSS, eventually forming the country's UPS or an independent power pool.

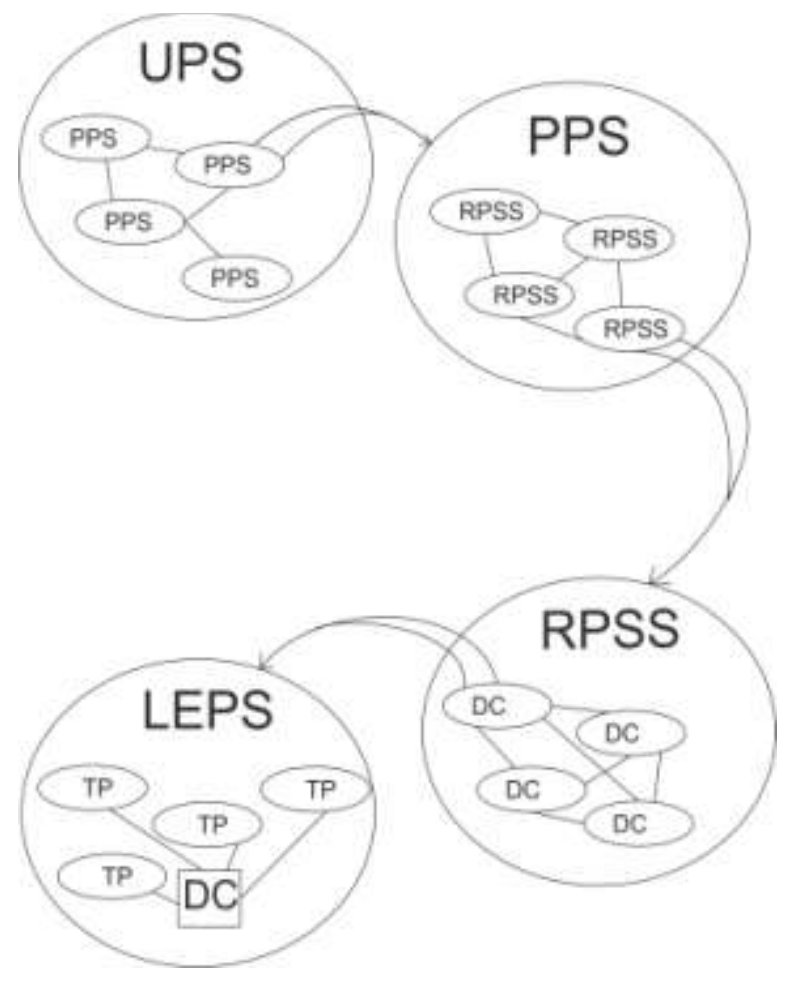

Fig. 2. Hierarchical representation of a power supply system.

It is offered to perform calculations of the reliability indexes of the power supply system - the regional group of points of electric supply, district centers of supply, local supply points and ultimate consumers. This approach enables to determine bottlenecks, to select and to justify the ways and means of improving the reliability of power supply systems without reducing their efficiency.

Calculated indices must take into account structural, object and performance parameters of the mains. Analysis and 
comparison of indexes will allow not only identifying bottlenecks, but also examining causes of the reliability reduction, and most importantly, determining priorities which help to improve the reliability of power supply to consumers.

\section{PROBLEM DEFINITION AND WAYS OF SOLUTION}

In Russia as in all countries, the reliability level of power supply depends on material and other funds for providing and maintenance of non-failure operation and recoverability of the equipment and technological processes.

At the level of UPS and PPS, the value of a reliability index depends on the generation companies (GC) which bear responsibility for production of the electric power volume demanded by consumers. It is well known that the integration of RPSS is followed by the reduction of requirements for the size of the power reserve allowing one to maintain reliability at the set level. The result is reached due to mutual back-up of the power plants of different regions. Thus, it is possible to increase reliability without reducing profitability mostly by means of using a great number of trouble-free electric generators causing physical worn-out and obsolete units.

Due to economical reasons, a standard indicator of the balance reliability in the Soviet period has decreased from 0.999 to 0.996 . Nowadays, the target is to increase the probability of sufficient operation of power supply systems to 0.9997 to reach foreign standards of power system reliability (the USA - 0.9997, France - 0.9997, the Netherlands 0.9995, Ireland - 0.9991 [4]).

It is important to note that the capacity of currently available power plants exceeds a loading maximum almost 1.5 times. The capacity factor reflects unrealized opportunities of electricity generation. Input of new capacities along with the decrease of power consumption in the country means the lack of the reliability problem at the UPS level. However, this problem is critical for PPS of Far East.

Existing RPSS rarely have their own generating capacity stand-by for full self back-up due to its economical inexpediency. The size of a back-up is determined by restrictions from a backbone network $[5,6]$.

Within RPSS, the reliability of power supply can be increased by construction of new transmission lines, reconstruction of the old ones or using distributed generation, which can guarantee profitability and reliability of power supply to end-consumers.

Another way of increasing reliability of RPSS is a districtdecentralized power station. Nowadays, a big problem is joining distributed resources with Electric Power Systems due to various restrictions, introduced by the rules of technological connection of distributed generation to the network, rules of the retail market, imperfections in technology and technology management of modes. However, the Russian state takes measures to reduce the cost of connection of distributed generation to the network by new standards, determining power outage frequency and duration.

\section{POWER SUPPLY RELIABILITY INDEX}

The model and the method of calculation of a power standby, in accordance with principles of self and mutual back-up, in the integrated power system is fully represented in [7]. The proposed method considers available power plant capacity, generation reliability, power transmission capacity and required balance reliability indexes of regional systems.

Balance reliability index $\mathrm{J}_{\mathrm{I}}$ can be calculated, knowing the probability of energy undersupply in each part of the region unification $(\mathrm{A})$.

$$
J_{l}=\prod_{i=1}^{A} J_{r_{i}}{ }^{k_{i}}
$$

$\mathrm{J}_{\mathrm{ri}}{ }^{\mathrm{k}_{\mathrm{i}}}$ - balance reliability index for $\mathrm{r}_{\mathrm{i}}$ region;

$0 \leq \mathrm{k}_{\mathrm{i}} \leq 1 / \mathrm{A}$ - regional self-sufficiency factor that depends on stand-by capacity for self back-up. If the balance reliability is provided due to mutual back-up, this factor tends to zero.

Table 2 shows the dependence of the balance reliability index on stand-by capacity for 9 regional power supply systems of PPS of Siberia [6]. Reducing the total size of standby capacity allows evaluating the system effect of RPSS integration.

TABLE II. RPSS RELIABILITY INDEX

\begin{tabular}{|l|l|c|c|c|c|}
\hline Region & $\begin{array}{c}\text { Self back-up } \\
\text { stand-by, } \\
\text { MW }\end{array}$ & $\begin{array}{c}\text { Mutual } \\
\text { back-up } \\
\text { stand-by, } \\
\text { MW }\end{array}$ & $\begin{array}{c}\text { Self- } \\
\text { sufficiency } \\
\text { level of } \\
\text { balance } \\
\text { reliability } \\
\text { positions }\end{array}$ & $\begin{array}{c}\text { Balance } \\
\text { reliability } \\
\text { index }\end{array}$ & $\begin{array}{c}\text { Self- } \\
\text { sufficiency } \\
\text { factor values }\end{array}$ \\
\hline 1 & 131.2 & 121.9 & 0.929 & 0.992 & 0.06 \\
\hline 2 & 174.4 & 0 & 0 & 0.876 & 0 \\
\hline 3 & 519.7 & 356.8 & 0.686 & 0.973 & 0.03 \\
\hline 4 & 1649.9 & 522.8 & 0.317 & 0.929 & 0.01 \\
\hline 5 & 621.3 & 569.4 & 0.916 & 0.987 & 0.04 \\
\hline 6 & 54.8 & 54.8 & 1 & 0.996 & 0.11 \\
\hline 7 & 80.3 & 66.6 & 0.829 & 0.963 & 0.01 \\
\hline 8 & 65.9 & 65.9 & 1 & 0.996 & 0.11 \\
\hline 9 & 161.8 & 109.9 & 0.679 & 0.975 & 0.03 \\
\hline$\sum$ & 3459.3 & 1868.1 & - & 0.995 & - \\
\hline
\end{tabular}

A self-sufficiency level is determined by a ratio of standby capacities, necessary for the region in case of existence and absence of mutual assistance from adjacent regions. The value of the self-sufficiency level allows one to judge how the region balance reliability depends on supplies from adjacent regions.

The regional index of balance reliability can be calculated without taking into account mutual back-up, if the selfsufficiency level is determined, using the distribution function of sufficient power supply. 
Another indicator that reflects the reliability of power supply is the ratio of regional unbalance and power capacity of mutual back-up. The higher this indicator, the more the network is to ensure reliability. Using the data from table 1, it is possible to calculate the reliability index of integration.

This example shows that the PSS index of reliability is slightly lower than the normative value, which means that it is necessary to provide a possibility of a back-up from another PPS. Strengthening interconnections 2, 4, 7 and 9 with the RPSS allows one to reduce their self-sufficiency factor values. There is another possibility of increasing stand-by capacity and placing them in RPSS 2 and 4. The choice will be defined by technical and economic efficiency of the compared options. According to the example, increasing stand-by capacity is preferable due to availability of capacity at Hydroelectric power stations (HPS) in the fourth and seventh regions.

\section{POWER SUPPLY RELIABILITY OF POWER CENTERS}

In each region of the country, there is often only one RNO, which owns and manages the supply network and the power centers. The supply network is usually redundant, a considerable share of regional substations are loaded less than $75 \%$ of the transformer installed capacities, which leads to a reduction of DC reliability.

The power supply reliability index of DC can be calculated with the use of current and standard availability factors. The method of calculation is described in [8]:

$$
\mathrm{M}_{\mathrm{i}}=\mathrm{K}_{\mathrm{i}}{ }^{\text {cur }} / \mathrm{K}_{\mathrm{i}}^{\text {stand }} \text {, }
$$

where $\mathrm{K}_{\mathrm{i}}^{\mathrm{cur}}$ - current availability factor;

$\mathrm{K}_{\mathrm{i}}^{\text {stand }}$ - standard availability factor

The standard availability factor reflects the necessary level of no-failure operation and recoverability of the supply network. Ratio $\mathrm{M}_{\mathrm{i}}$ allows revealing bottlenecks in RPSS.

Each DC has its own reliability index $M_{i}$. By finding $M_{i}$ for each region substation, the generalized index for a region can be determined:

$$
J J_{\mathrm{p}}=\sum_{1}^{k} M_{\mathrm{i}} * S_{i} / \sum_{1}^{k} S_{i}
$$

where $\mathrm{k}$ - number of regional substations,

\section{$\mathrm{S}_{\mathrm{i}}$ - load capacity of consumers}

The ratio of $\mathrm{M}_{\mathrm{i}}$ and $\mathrm{JJ}_{\mathrm{p}}$ reflects the uninterrupted supply level for each region. The region is considered to have a sufficient reliability level, if this ratio is positive. Otherwise, there is a need of increasing the supply network reliability.

Also, for deeper analysis of the reliability level, it is offered to calculate indexes of reliability not only from an availability position, as it is shown in (3) and (4). The great influence on the power supply reliability is exerted also by an operating mode of the DC and wear-out of the equipment.
Considering load position the reliability index of DC is a ratio of DC load capacity of consumers in the maximum mode and capacity of DC transformers (while taking into account the criterion of (n-1)) multiplied by the basic reliability index of DC from point of view of availability position $\left(\mathrm{M}_{\mathrm{i}}\right)$ :

$$
\mathrm{L}_{\mathrm{i}}=\mathrm{M}_{\mathrm{i}} \cdot\left(\mathrm{S}_{\mathrm{i}}^{\max } / \mathrm{P}_{\mathrm{i}}{ }^{\text {trans }}\right) \text {, }
$$

where $\mathrm{P}_{\mathrm{i}}{ }^{\text {trans }}$ - capacity of transformers;

$\mathrm{S}_{\mathrm{i}}{ }^{\mathrm{max}}$ - load capacity of consumers in the maximum mode.

If one considers wear-out position, the reliability index of DC can be calculated as a ratio of the operation period of DC and the standard operation period of main equipment, multiplied by $\mathrm{M}_{\mathrm{i}}$ :

$$
\mathrm{W}_{\mathrm{i}}=\mathrm{M}_{\mathrm{i}} \cdot\left(\mathrm{T}_{\mathrm{i}} / \mathrm{T}^{\text {stand }}\right),
$$

where $T_{i}$ - operation period of DC (or the number of years after reconstruction);

$\mathrm{T}^{\text {stand }}-$ standard operation period of main equipment.

According to the calculations distribution of index values of power supply reliability of DC, relative to the regional index, allows one to form RNO technical development policy.

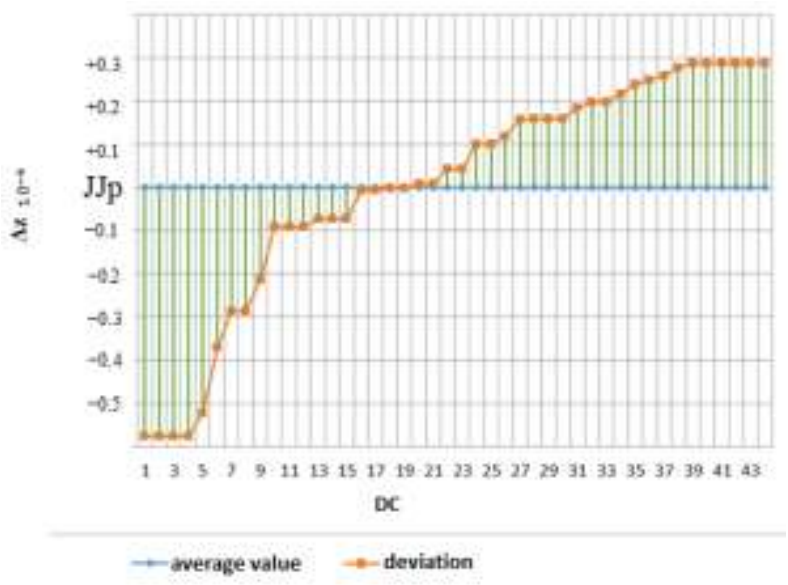

Fig. 3. The ratio of the Power supply reliability index and the generalized index.

It is necessary to find an optimal solution with minimum expenses because of certain economic, temporary and other restrictions. It is a problem of search and elimination of bottlenecks in the system.

For this purpose, it is necessary to consider ratios of DC indexes by the considered criteria and the regional indexes, corresponding to them. It would allow defining DC, which work least effectively. Mathematically the solution of this task is a crossing of the DC sets, which are located in a negative part of the schedule (for example, figure 3 ).

$$
\mathrm{X}=\mathrm{M} \cap \mathrm{L} \cap \mathrm{W}
$$


$\mathrm{M}, \mathrm{L}, \mathrm{W}$ - set of substations identified by availability, load and wear factors;

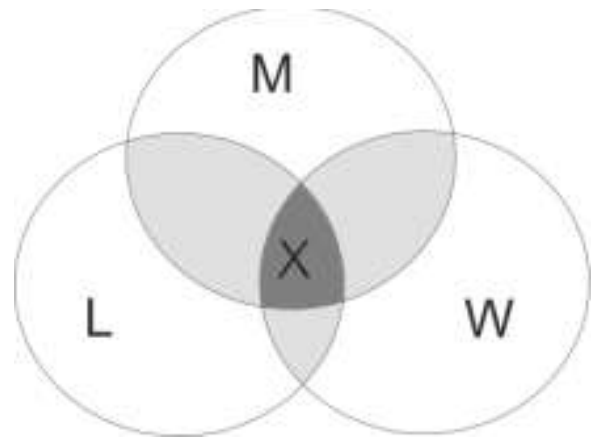

Fig. 4. Identification of bottlenecks.

It is necessary to point out the use of composite structural elements of OTL as a technical mean of the increasing reliability of the supply network. During the reconstruction of OTL, it is preferable to use composite beams and composite wires to increase OTL's non-failure operation twice. Using composite poles allows increasing restorability due to their well-known properties of reduced recovery time.

Being connected to buses of $10 \mathrm{kV}$ DC of distributed generation can be another option with the possibility of having additional effects. For example, using gas turbine units and combined-cycle power units makes it possible to perform OTL back-up, to align the load schedule of $10 \mathrm{kV}$ buses, to reduce energy losses as well as to increase supply quality.

Calculations have shown that the physical condition and extent of transformers load of DC should be taken into consideration the installation point choice of distributed generation. The example of specific RPSS shows changes in reliability indexes due to the use of these technical means.

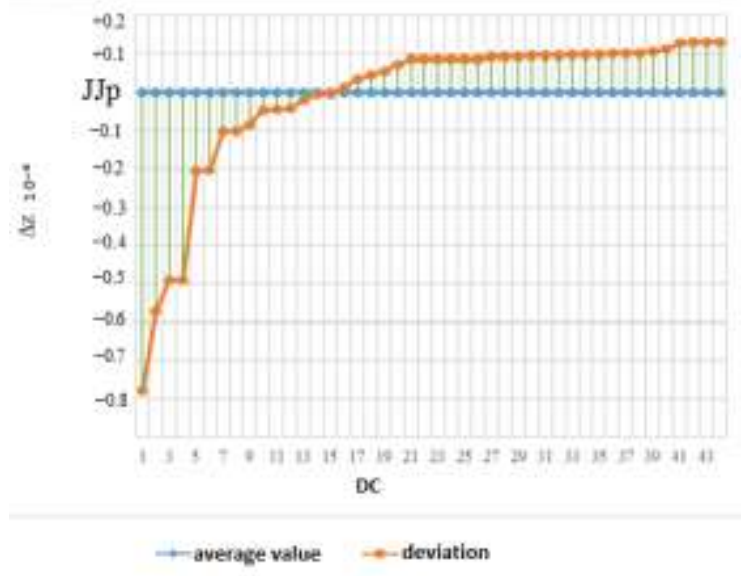

Fig. 5. The change in the index after connection of distributed generation.

This schedule shows that the distributed generation is an effective solution of increasing reliability that allows one to align the DC reliability level. Before modeling actions to access the distributed generation, 19 of 43 DCs of the analyzed RPSS had the reliability index below the regional value. Taken measures made it possible to have the value of the regional index close to $70 \%$. Only 15 DCs, which is now $34 \%$, have the index value below the required value. It shows that the quantity of ineffective DC in the considered RPSS has decreased by $10 \%$.

However, it is necessary to specify that connection of the distributed generation to DC buses does not affect the reliability of power supply of TP included in LEPS. In this case, the source of distributed generation should be connected to buses of $10 \mathrm{kV}$. At the same time, their capacity can be reduced to 5-10 MW, which corresponds to capacities of a huge number of boiler plants. Thus, having a boiler plant in the cogeneration mode during reconstruction allows increasing power supply reliability and fuel utilization efficiency.

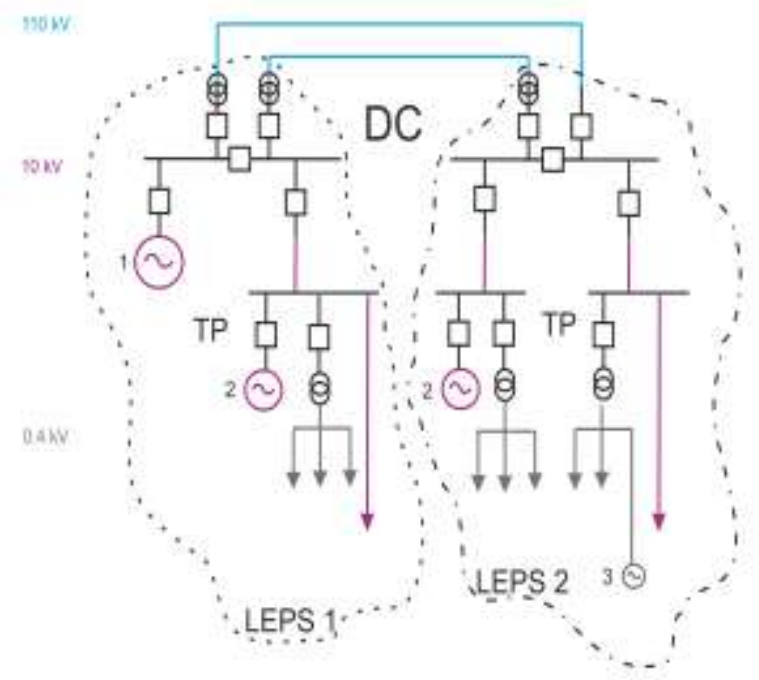

Fig. 6. Connection of the distributed generation to buses.

\section{POWER SUPPLY RELIABILITY}

It was mentioned above that distribution networks of 6$35 \mathrm{kV}$ provide the reliability of power supply to customers, connected to the step-down side of the transformer center. Therefore, uninterrupted operation of power supply to consumers depends on the reliability of electrical supplies to TP.

The LEPS distribution network has a radial structure without an ability of mutual back-up. To provide an sufficient reliability level, consumers with increased requirements need to be connected to two different TP. However, this problem can be solved by using sources of distributed generation $(0.1$ to $1.0 \mathrm{MW}$ ) and sufficient storage devices. Having a source on substation busbars allows increasing the power supply reliability due to distribution network back-up.

According to efficiency analysis [9], LEPS should be developed by creating control system available to implement SMART GRID conception.

The reliability index of power supply for each $\mathrm{TP}\left(\mathrm{W}_{\mathrm{s}}\right)$ is: 


$$
\mathrm{W}_{\mathrm{s}}=\left(\mathrm{K}_{\mathrm{s}}{ }^{\text {cur }} \cdot \mathrm{K}_{\mathrm{g}}{ }^{\text {cur }}\right) /\left(\mathrm{K}_{\mathrm{s}}{ }^{\text {stand }} \cdot \mathrm{K}_{\mathrm{g}}{ }^{\text {stand }}\right) \text {, }
$$

where $\mathrm{K}_{\mathrm{s}}{ }^{\text {cur }}, \mathrm{K}_{\mathrm{s}}{ }^{\text {stand }}$ - current and standard value of the availability factor of each TP;

$\mathrm{K}_{\mathrm{g}}{ }^{\text {cur }}, \mathrm{K}_{\mathrm{g}}$ stand - current and standard value of the availability factor of each $\mathrm{SG}$, connected to TP;

s- number of TPs;

g- number of connected SGs.

The reliability index of LEPS power supply $\left(\mathrm{JJJ}_{\mathrm{s}}\right)$ is:

$$
J J J_{s}=\sum_{1}^{m} W_{s} * S_{j} /\left(\sum_{1}^{m} S_{j}-\sum_{1}^{m} \sum_{1}^{n} P_{j n}\right),
$$

where $\mathrm{m}$ - number of TPs in a region ( $\mathrm{s}) ; \mathrm{S}_{\mathrm{j}}-\mathrm{TP}$ 's load; $\mathrm{n}$ - number of SG connected to TP; $P_{x}$ - power capacity of SG.

Using value $\left(\mathrm{W}_{\mathrm{s}}\right)$, it is possible to calculate standard indicators of the power supply reliability, such as SAIDI, SAIFI, CAIDI, ASIFI, ASIDI, AENS, ASAI [10]. The data set of indicators reflects the uninterrupted power supply for each consumer connected to TPC.

SAIDI and SAIFI are commonly used as the main indicators of the power supply reliability. They reflect frequency and duration of power consumption restrictions. It is possible to determine standard indexes of power supply for TP and LEPS by rationing these indexes for consumers of different categories. Thus, it will be possible to reveal bottlenecks of distributive networks and to select appropriate technical means of increasing their reliability level.

In this part, it is offered to pay attention to possibilities of distributive network islanding due to recloser use as means of the system of the decentralized management of a network condition. Their efficiency is obvious in the presence of long 10-35 kV OTL with intermediate withdrawal. This automatics makes it possible to increase SAIDI and FAIFI values of certain consumers connected to the same TP.

\section{CONCLUSION}

1. The level of the reliability of power supply is offered to be estimated by a set of the indexes, reflecting the degree of uninterrupted operation of power supplies to the pooled, regional, district and local electrical power subsystems.
2. Approaches and appropriate methods of indexes calculation of power supply reliability, reflecting the particularities and specificities of each hierarchical level, their structural, object and performance parameters are developed.

3. The index value allows defining expediency of improving indicators of non-failure operation and recoverability of the power system units and carrying out innovative technical facilities due to a raise of the reliability level without profitability decrease.

\section{References}

[1] B. Auev, "Technical regulations for market elements" Expert, vol. 44 (921), 2014

[2] A. Murov, "I want the rules of power engineering to change rarely" Vedomosti, Vol. 3753 21.01.2015.

[3] F.Byk., L.Kazakova, "Efficient Ways and Means of Reliability Increase of Distribution Networks", Applied Mechanics and Materials, vol. 792, pp. 280-285, 2015

[4] Yu. Churkeev, M. Churkeev, The comparative analysis of probabilistic indicators of balance reliability and the methodical principles of their definition at management of development of electrical power systems, Syktyvkar, Scientific Center of Ural Branch of the Russian Academy of Science, 2012

[5] The provision on definition of the long-term tariffs of indicators of reliability and quality of the delivered goods and the rendered services applied at establishment approved by the Resolution of the Government of the Russian Federation of December 31, 2009. № 1220

[6] V. Ovseychuk, S. Shimko,"Economically valid reliability setting of electric power supply", Herald of Russian Academy of Natural Sciences, vol. 1, pp. 111-112, 2013

[7] F. Byk, V. Kitushin, M. Nizhnikova, L. Myshkina, "The method of adequacy estimation developed for the electric power system", 11 International forum on strategic technology, part. 2, pp. 213-217, June 2016 [11 International forum on strategic technology (IFOST 2016), p. 621, 2016]

[8] V. Oboskalov, Structural reliability of electrical power systems: textbook, Ekaterinburg: Publishing House Ural Federal University, 2012.

[9] M. Rodionova, "The distributed generation comes out of the shadow", Electric power. Transmission and distribution, vol.3 (30), pp 116-121, 2015

[10] L. Willis, Power Distribution Planning Reference Book, Power Engineering, CRC Press, 2004. 